\title{
Use of Drying Technologies for Resource Recovery from Solid Wastes and Brines
}

\author{
Kanapathipillai Wignarajah ${ }^{1}$ and Ric Alba. ${ }^{2}$ \\ Dynamac Corporation, NASA-Ames Research Center, Moffett Field, CA 94035-1000 \\ John W Fisher ${ }^{3}$ and John A Hogan ${ }^{4}$ \\ NASA-Ames Research Center, Moffett Field, CA 94035-1000 \\ and \\ Alex Polonsky ${ }^{5}$ \\ Foothill Intern, NASA-Ames Research Center, Moffett Field, CA 94035-1000
}

\section{Abstract}

Long term storage of unprocessed biological wastes and human wastes can present major health issues and a loss of potential resources. Space vehicles and planetary habitats are typically resource-scarce or resource-limited environments for long-term human habitation. To-date, most of the resources will need to be supplied from Earth, but this may not be possible for long duration human exploration. Based on present knowledge, there is only very limited in-situ resources on planetary habitats. Hence, the opportunity to "live off the land" in a planetary habitat is limited. However, if we assume that wastes generated by human explorers are viewed as resources, there is great potential to utilize and recycle them, thereby reducing the requirements for supply Earth and enabling the "live off the land" exploration scenario.

Technologies used for the recovery of resources from wastes should be reliable, safe, easy to operate, fail-proof, modular, automated and preferably multifunctional in being capable of handling mixed solid and liquid wastes. For a lunar habitat, energy does not appear to be the major driving factor amongst the technologies studied. Instead, reliability appears to be more important ${ }^{[1]}$. This paper reports studies to date on drying technologies to remove water from solid wastes and brines. Experimental performance data obtained for recovery water from wastes and brine are presented. Simplicity of operation of hardware and energy efficiency are discussed. Some improvements and modifications to hardware were performed. Hopefully, this information will assist in future efforts in the "downselection" of technologies for recovery of water and resources from solid wastes and brines.

\section{Nomenclature}

BVAD Baseline Values and Assumptions Document

EMC Electro Magnetic Compatibility

ESM Equivalent System Mass

IGBT Integrated Gate Bipolar Transistor

ISM Industrial, Scientific and Medical

MW Microwaves

\footnotetext{
${ }^{1}$ Senior Scientist, Dynamac Corporation, NASA-Ames Research Center, MS 239-8, Moffett Field, CA 94035, USA

${ }^{2}$ Engineer, Dynamac Corporation, NASA-Ames Research Center, MS 239-8, Moffett Field, CA 94035, USA

${ }^{3}$ Lead Engineer-Life Support, NASA-Ames Research Center, MS 239-8, Moffett Field, CA 94035, USA

${ }^{4}$ Engineer, NASA-Ames Research Center, MS 239-8, Moffett Field, CA 94035, USA

${ }^{5}$ Foothill Intern, NASA-Ames Research Center, Moffett Field, CA 94035-1000 
RF Radio Frequency

VOC Volatile Organic Compounds

WRS Water Recovery System

\section{Introduction}

Wastes will inevitably be generated during any human space missions. Solid wastes and brines generated in spacecraft and habitats present potentially major biological and chemical hazards during space missions and in space habitats. Typical solid wastes include plastics, unused and partially used food wastes, human feces. Typical weights of the various wastes generated have been previously documented in numerous reports, but there has always been some concerns and uncertainties on fidelity of the values reported. A recent document by Fisher et al (2010) ${ }^{[2]}$ has provided more clarity and reduced the uncertainties in the values of wastes and brine generated in space habitat. This document has reviewed literature to-date and is expected to be part of the upcoming revised version of the 2010 Baseline Values and Assumptions Document (BVAD).

Brine is generated from processing of water in space habitats (Table 1). The major wastewaters include hygiene wastewater, humidity condensate and urine. Brine generated from the water recycling system (WRS) can have as much as $20 \%$ solids. Typically, most of the solids in the wastewater come from urine with only minor contributions from hygiene/laundry water in the form of abrasives and/or soaps. A major concern of the brine currently generated is the highly acidic nature of the brine. The low $\mathrm{pH}$ results from the current wastewater collection and storage procedure that employs the use of sulfuric acid and oxone to reduce the $\mathrm{pH}$ to approximately 2 . This reduces the release of ammonia and prevents growth of microorganisms in the wastewater stream. Currently, NASA has funded efforts in progress to re-evaluate this protocol and it is likely that in future, technologies for storing urine and wastewater may likely not require the use of such highly acidic solutions.

Table 1. Nominal loads of Brine generated in a space habitat ${ }^{[2]}$.

\begin{tabular}{|l|l|l|}
\hline & $\mathrm{g} / \mathrm{CM} /$ day & Brine generated $(\mathrm{g})$ \\
\hline Hygiene Wastewater & 7170 & 79.2 \\
\hline Humidity Condensate & 2270 & 1.3 \\
\hline Urine & 1562 & 330 \\
\hline Total & 11002 & 410.5 \\
\hline
\end{tabular}

THERMAL DRYING TECHNOLOGIES - Conventional and Novel technologies.

Traditional drying technologies used are thermal in nature. Thermal drying technologies are very intensive and require the application of heat directly on waste materials remove any water. Thermal heating can involve conventional application of heat or novel types of heating such as dielectric heating, RF and microwave heating, and Ohmic/Joule heating.

Conventional (Surface) heating.

Conventional thermal heating (or surface heating) relies on production of heat using electrical resistive heaters or combustion of fuel outside of the waste and the transference of the heat through conductive and or convection mechanisms through the material to be dried. The process time is limited by the rate of heat flow into the body of the waste material from the surface as determined by the specific heat, thermal conductivity, density and viscosity of the waste material. Surface heating is not only slow, but also non-uniform with the surfaces, edges and corners being much hotter than the inside of the material. Consequently, the quality of conventionally heated materials is variable and frequently inferior to the desired result. In addition, they are energy inefficient because much of the heat is lost as radiant energy. 
Dielectric heating

Dielectric heating involves interaction between an alternating electromagnetic alternating field as well as the dipoles and ionic charges contained within the waste material to be dried. Microwaves (MW) and radio frequencies (RF) heat the volume of the material (volumetric heating). In this process, water and ionic species in the waste material undergo fast molecular movements in response to microwaves $(300-30000 \mathrm{MHz})$ and RF (1-300MHz). Using RF and microwaves it is possible to heat specific components; this heating rate is several fold higher than heating by conventional methods. Du et al has shown that microwave drying of wood saved up to $50 \%$ energy consumption and showed over a 10 -fold reduction in the release of volatile organic compounds (VOC) compared to conventional oven drying $^{[3]}$. RF and MW, however, do not have sufficient energy $(<10 \mathrm{eV})$ to ionize atoms and hence they are referred to as non-ionizing radiations. Nationally and Internationally determined Electro Magnetic Compatibility (EMC) regulations govern and restrict the frequencies permissible for heating purposes. Permissible frequency bands for heating in Industrial, Scientific and Medical (ISM) are indicated in Table 2.

Table 2: Approved ISM frequency bands for heating

\begin{tabular}{|l|l|}
\hline Dielectric Heating & Frequency (in MHz) \\
\hline Microwave & $8.960 \times 10^{\wedge^{2}}(\mathrm{UK})$ or $9.150 \times 10^{\wedge^{2}}(\mathrm{EUA})$ \\
\hline & $2.450 \times 10^{\wedge^{3}}$ \\
\hline & $5.800 \times 10^{\wedge^{3}}$ \\
\hline & $2.4125 \times 10^{\wedge^{4}}$ \\
\hline Radio Frequency & $1.356 \times 10$ \\
\hline & $2.712 \times 10$ \\
\hline & $4.680 \times 10$ \\
\hline
\end{tabular}

Both RF and MW provide non-contact volumetric heating but since the RF frequencies are much higher than the MW heating, RF energy provides much higher penetration of the material than MW.

Ohmic heating

Ohmic (Joule) heating is a process that came to attention in the 1980's but has been neglected in the past 5 years. Ohmic research involves direct heating of the material by an electric current. The material serves as an electrical resistor and the electricity is applied directly and hence very little loss of energy ${ }^{[4]}$. The electrical energy helps drive the water off and sterilize the materials. A design and development consideration for processing and heating food for astronauts has been previously reported $\mathrm{d}^{[5]}$. The paper assumed an availability of DC supply power on space station and showed that for heating of food the Equivalent System Mass (ESM) was in the region of 40-60 kg. The DC supply was connected through an Integrated Gate Bipolar Transistor (IGBT) module to transform the rectified DC into AC signals in square waveforms. This is likely to be a technology worthy of future consideration, since ohmic heating can be designed to control electrochemical processes. Thermal heating can typically cause off-gassing and release of volatiles. Controlled ohmic heating under the appropriate conditions has been shown to restrict electrolysis and electrochemical reactions.

\section{Materials and Methods}

A number of small business innovative research (SBIR) prototype hardware for dewatering and processing of wastes and brines has been delivered to Ames Research Center (ARC). The functioning of this hardware has been documented in detail by Fisher et al ${ }^{[1]}$. Considerable "shake-down" testing of the hardware to process solid wastes and brines has been carried out and reported in previous ICES conferences ${ }^{[1,6,7,8,9,10,11]}$.

Closed Loop Drying Technology - A phase II SBIR/STTR closed loop dryer prototype, developed jointly by Orbitec Technology and Cornell University was delivered to ARC in 2008. The design, function and operating procedure of this hardware has been previously reported ${ }^{[11]}$. The system is designed to operate at a setting of $60{ }^{\circ} \mathrm{C}$. The closed loop dryer was tested to evaluate drying of solid wastes and simulated feces. The prototype at ARC in its present configuration it is not capable of being used to dewater liquid samples such as brine.

Microwave Drying Technology - The microwave powered solid waste stabilization and water recovery prototype was used in investigations of water recovery and drying of solid wastes, brines and mixed wastes. The air 
loop to drive the water released was closed as described later. Power usage was monitored using a Fluke power meter.

Some early reports on microwave drying of solid wastes and brines have been previously reported ${ }^{[6,7]}$. In these investigations, we studied the drying of a model wet trash as well as feces and brine under various combinations were studied. Based on previous studies, the microwave power setting was set to operate at $80 \%$ power that was shown to be optimal for energy use efficiency. Modifications were done to close the air loop.

Hardware Modifications - Closure of air loop

In the delivered configuration the microwave was designed to take single passes of air with the air being vented to the exhaust, in this case cabin air. The volume of the airline was estimated to be 82.7 liters. The blower (Elicent Type AXC, $100 \mathrm{~A}, 60 \mathrm{~Hz}, 55 \mathrm{~W}, 117 \mathrm{~V})$ operates as a setting of approximate airflow of $5.7 \mathrm{scfm}(161.3 \mathrm{slpm})$. Based on the computed volume of the airline, a single pass of air ( 82.7 liters) can be moved in 30 seconds. The air loop was closed by (1) connecting the original air inlet and the exit end of the air outlet with a U-shaped metal tube and (2) connecting the air exit end of the sample chamber and the inlet end of the air filter system with a flexible hose (see Figures $1 \mathrm{a} \& 1 \mathrm{~b}$ ). Figures $1 \mathrm{~A} \& \mathrm{~B}$ shows the image of the hardware before and after the modification.

Methods to Measure Water Removed from Samples

Two methods were used measure the amount of water removed from the sample waste materials that were dried. In the first method, we measured the amount of water collected in the condensate. This method assumes that all the water collected was derived only from the sample and all of it was condensed. In the second method, the sample was weighed before and after microwaving the waste material. This method assumes that microwaving removed only the water from the waste material.

\section{Results}

The closed loop dryer showed very low rates of water removal from wastes with the rates being in the order of 16-35 $\mathrm{g} \mathrm{h}^{-1}$ (mean of $20 \mathrm{~g} \mathrm{~h}^{-1}$ ) at a heater temperature of $60{ }^{\circ} \mathrm{C}$, condenser temperature of $24{ }^{\circ} \mathrm{C}$ and an air flow rate of 4.75 slps. Power consumption as measured at ARC was $0.41 \mathrm{~kW}$, but during this experimentation the system was not insulated. Estimates indicate that in an optimized version the power consumption could be reduced to $71 \mathrm{~W}$ that would indicate $17 \%$ efficiency in water removal. The poor performance can be due to a number of reasons, including considerable losses of heat on the surfaces of equipment and installations, reduction of heat transfer efficiency. In addition unless excessive heating of the wastes is prevented there can be release of volatiles which can be troublesome in a closed habitat. Some difficulties have also been experienced with failure of the heating elements and efforts will need to address such failures. Future work with the closed loop dryer needs to address these problems.

The closing of the loop has a number of advantages. In addition to using a limited amount of air, the system appeared to be more efficient. In the open loop system, however, there were discrepancies in the two methods used to measure the water extracted from the material. In the open loop system, we observed that the quantity of water collected from the condensate collected was $30-50 \%$ higher than the amount of water inferred to have been lost when using the weight measurement method. This discrepancy was most likely due to the fact that each loop of fresh room air contains atmospheric water vapor from the air in the room. When the system was operated in the closed loop configuration, there was no significant discrepancy in the quantity of water recovered by the two different methods. 


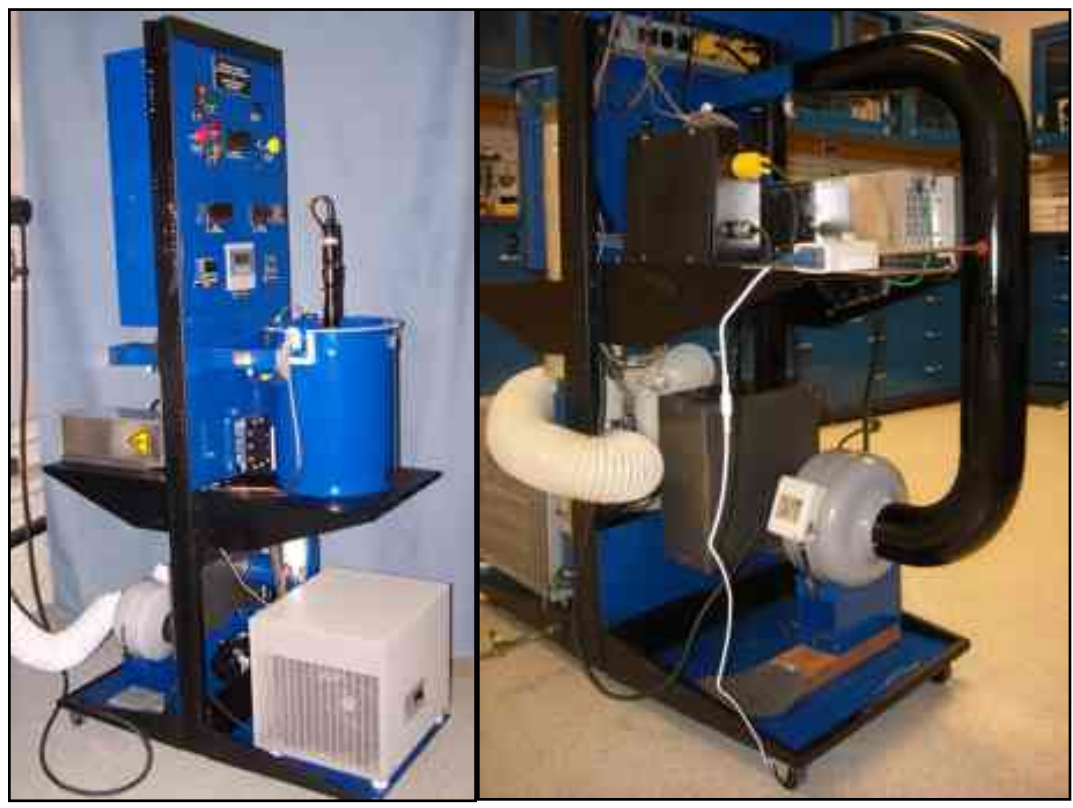

FIGURE 1. Microwave Powered Solid Waste Stabilization Unit - on the left (Figure 1a) the open loop system as delivered and on the right (Figure $1 \mathrm{~b}$ ) in the closed loop configuration.

Drying of wet trash.

Microwave drying of unprocessed wet trash showed that in some cases there was charring of the material often followed by the potential to catch fire. In these cases, the microwave system would shut off due to the waste temperature exceeding $80{ }^{\circ} \mathrm{C}$. Figure 2 shows the effect of microwaving a typical wet trash consisting of diapers, food wastes (left over food), paper etc. In this particular run, the automatic cut off system occurred due to the temperature exceeding $80^{\circ} \mathrm{C}$. Examination revealed that charring occurred, as evident by the browning seen on the surfaces of the diaper and on a celery stalk. Charring occurred only when unprocessed mixed wastes were microwaved and was observed in less than $10 \%$ of the runs. In some cases, as shown in Figure 3, when the oven was opened and the sample removed too quickly deflagration occurred as seen in Figure 3.

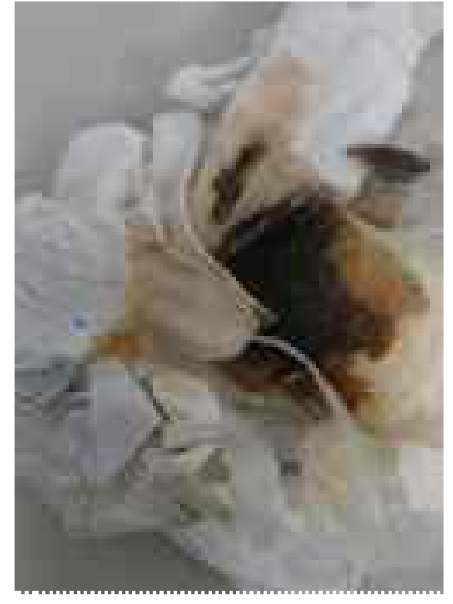

Figure 2 - Charred wet trash

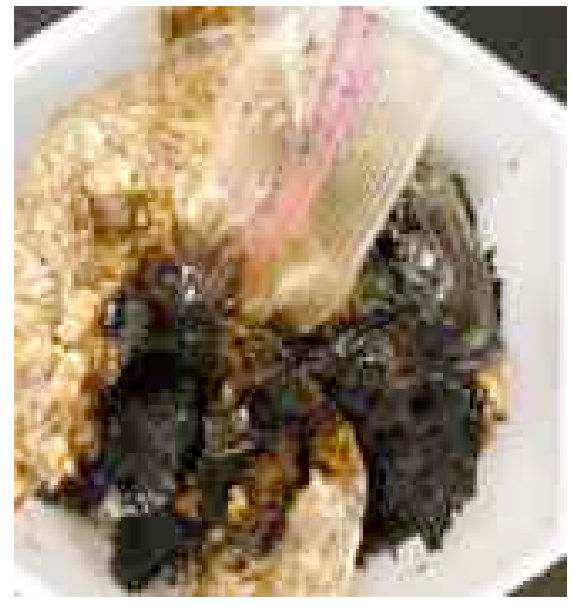

Figure 3 - Microwaved trash having deflagrated on exposure to air 
Occurrence of hotspots and non-uniform temperature distribution during microwave heating is not surprising and is one of the major challenges in the use of microwaves in food processing ${ }^{[12]}$. Pereira et al reported that charring could be prevented manipulating the air velocity and microwave power ${ }^{[13]}$. There are claims that use of Inverter Technology Microwave ovens designed by Panasonic can provide constant power continuously resulting in more uniform heating.

Drying of Brine Solutions

Some preliminary investigations into drying of brine were reported in the previous ICES conference ${ }^{[7]}$. Very high rates of water recovery (170 g/hour) were obtained. The residue was in the region of 5-7\%. Based on the known solid content of urine, water recovery rates of $85 \%$ in the WRS system and the known ratios of hygiene water and condensate water, one would expect the brine to have a solid content of $20 \%$. The lower than expected solids content could be attributed to a number of reasons. Two possible causes include suspected variations in the collection protocols as evident from the high variations in the total dissolved solids (TDS) of the initial urine samples, and the possibility of volatilization of brine and release of VOC's and volatiles.

Combinations of Feces and Brine

Since we had previously demonstrated excellent drying of simulated feces and since we recognized that presence of cloth and particles could cause charring to occur, we decided to test the presence of toilet tissue, paper and gloves in feces mixed with brine.

In the first set of microwave experiments, the waste materials was modified to include small fragments of nitrile gloves and large pieces of paper and tissue. We observed that some potential charring occurred as shown in Figure 6. Since liquid samples like brine were dewatered and dried without charring, it was proposed to test the effect of applying microwave heating to completely homogenized wastes

Table 3, shows the kinetics of drying of a $500 \mathrm{~g}$ sample made up of feces with gloves and toilet tissue and or brine. The water heating efficiency is based on thermally computed microwave energy delivered to the sample chamber. At full power this was determined to be $135 \mathrm{~W}$ and assuming that the power is linear with changes in the power rating, at $80 \% 108 \mathrm{~W}$ of energy should be delivered to the sample chamber. However, the very low conversion of the electrical energy to microwave is not satisfactory at $18 \%$. The magnetron is rated to $600 \mathrm{~W}$ and much of the electrical energy is dissipated as heat resulting in the need for excessive cooling of the system. The system is not a commercial optimized unit and was a home-made version. In fact, it does overheat and the magnetron had to be replaced due to damage. Clearly, it is far from optimized. There is a need for considerable improvements in this aspect to bring the system to acceptable standards. Even, commercial microwaves have around $40 \%$ conversion efficiency and new solid state versions with much higher efficiencies are likely to be available commercially in the future that can be considered.

Table 3: Drying Kinetics and Energy Efficiency during Microwave Drying of Simulated Feces and Brine

\begin{tabular}{|l|l|l|}
\hline Parameter & Feces & Brine \\
\hline Sample size & $500 \mathrm{~g}$ & $500 \mathrm{~g}$ \\
\hline Rate of drying & $135 \mathrm{~g} / \mathrm{hour}$ & $170 \mathrm{~g} / \mathrm{hour}$ \\
\hline Total Energy Consumption & $1.375 \mathrm{kWh}$ & $1.375 \mathrm{kWh}$ \\
\hline Microwave Energy & $108 \mathrm{~W}$ & $108 \mathrm{~W}$ \\
\hline Microwave Rating & $600 \mathrm{~W}$ & $600 \mathrm{~W}$ \\
\hline Estimated Microwave Efficiency & $18 \%$ & $18 \%$ \\
\hline Water Heating Efficiency & $91 \%$ & $106 \%$ \\
\hline
\end{tabular}

Preprocessing/homogenization of wastes.

In order to homogenize the waste brine was added to the solid waste, in this case simulated feces with gloves, tissue and wipes. Homogenization of the waste sample was performed in a heavy-duty blender for approximately 30 minutes and until it was visible that all the paper was blended in and the sample was almost totally fluidized. Figure 4 shows the appearance of the unblended simulated feces, gloves and paper with brine. Figure 5 shows the heavily blended (pureed) sample. The typical daily ratio of fecal wastes to brine based on a 6-person crew is around $120 \mathrm{~g}$ to $410 \mathrm{~g}$ and this was used in the investigations. In addition, toilet tissue, disinfectant wipes and gloves were added. 


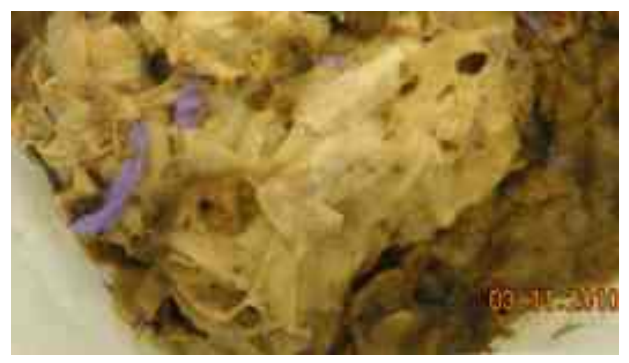

Figure 4: Unblended waste of simulated feces, gloves, toilet paper and brine

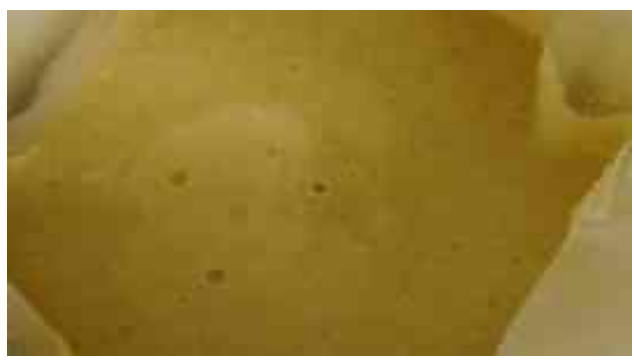

Figure 5: Pureed waste of simulated feces, gloves, toilet paper and brine

Both the unblended and pureed samples were heated using the microwave power supply set at $80 \%$ for 4 to 5 hours. With the unblended waste at about 4.75 hours, it was observed that the waste temperature was beginning to reach $80 \mathrm{C}$ at which point it was decided to manually abort the microwave heating. Close observation of the blackened/burnt regions suggested that the hot spot was located in some of the heavy disinfection wipes that were included and possibly the non-shredded toilet tissue.

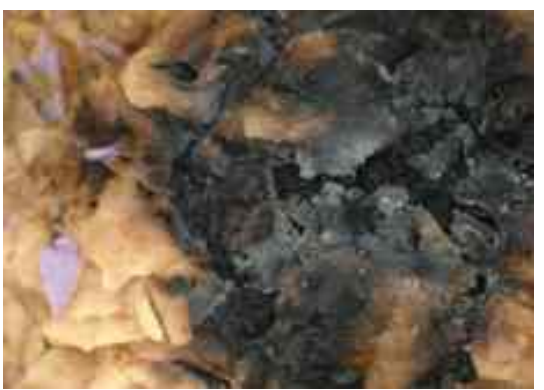

Figure 6 - Non-homogenized waste after 4.75 hours of microwaving

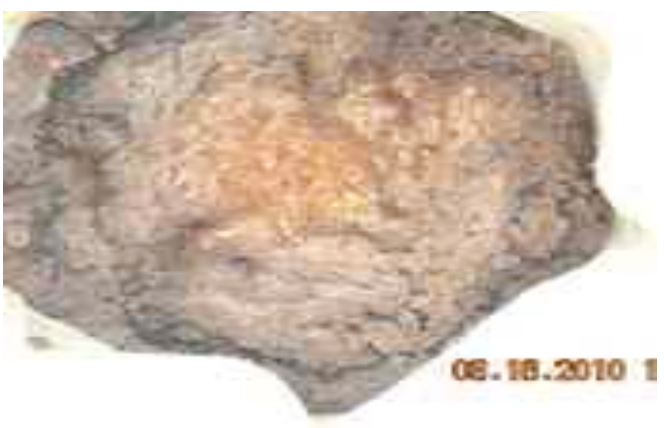

Figure 7 - Blended waste after 4.5 hours of microwaving

As is evident in Figure 6, the material burnt. On the other hand, the blended waste showed very uniform drying (Figure 7) and rate of water removal was in the region of $145 \mathrm{~g} /$ hour.

Continuous Feeding of the Waste into the Microwave Chamber

Other modifications for consideration in the future is a design for continuous feed of the waste. Similar semicontinuous feed system for drying radioactive liquid waste has been commercialized. A conceptualized schematic of the continuous feed automated microwave system for processing wastes is shown in Figure 8. Assuming based on our studies that there will be a need to homogenize the wastes before drying and water recovery, it may now be feasible to pump all the wastes into a homogenizer that in turn will pump the wastes as a slurry into the sampling chamber. This is not a new concept and in fact most previous efforts at drying and dewatering wastes have considered a pre-processor. Clearly, it will need to be fail-proof and be capable of both shredding and cutting the wastes. It could also incorporate an auger-type feed system. Once the waste is fed into the chamber, the microwave power can be automatically activated to begin the drying and water recovery process. Control systems to detect the dryness of the waste sample and the moisture content of the air bringing the recovered water could serve to trigger and activate the waste feed system so that the system operates continuously. To facilitate disposal and easy management of the dried wastes, the drying chamber can be lined with appropriate bags. Litwiller designed solid and liquid waste drying bags for processing of human wastes ${ }^{[14]}$. This was specifically designed for the Fecal Membrane Commode (FMC) and to be microgravity compatible but this could be compatible for the purpose of the microwave assisted waste processor. 


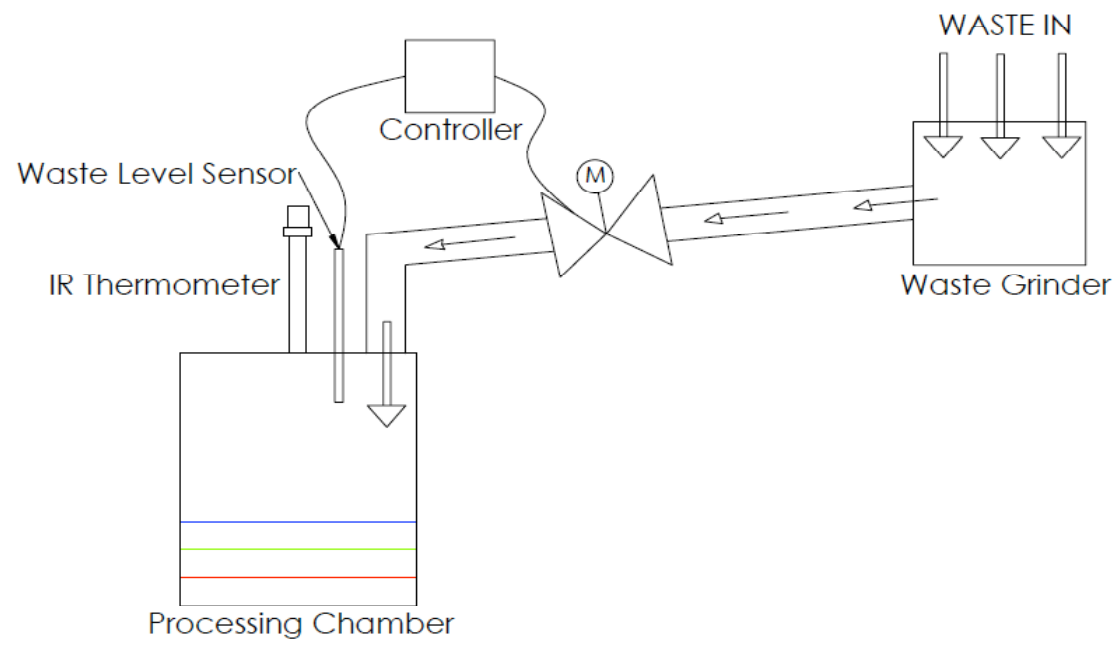

Figure 8 - A hypothetical schematic of a Design of an Automatic Microwave Assisted Waste Processor.

Continuous Operation of Microwaves

In the present design, microwaves operate on a time average, full on/ full off. Such drastic changes result in thermal runaway and are considered the likely reasons for the charring and burning of the materials. Progress in inverter technology that incorporates a constant supply of power may help to prevent this problem. In the Panasonic inverter technology, an inverter circuit replaces the bulky transformer. Figure 9 shows the modification as represented in the Panasonic manual.
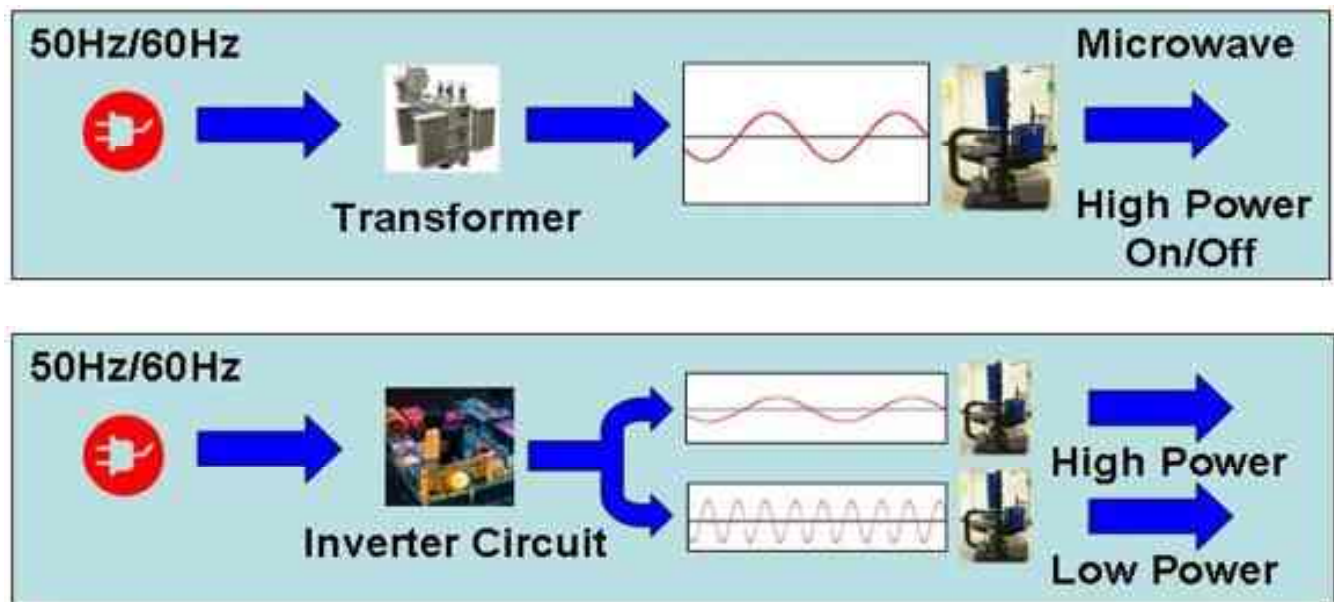

Figure 9 - Schematic showing the differences between a Standard Microwave (top) and an Inverter Technology Microwave.

The advantage of the inverter technology is that the application of microwave energy is gentler and more uniform. In addition, by providing appropriate feedback control mechanisms, the power applied can be automatically adjusted to suit the energy required to dry the sample to the desired sample moisture level. Using this strategy, Pereira et al produced high quality dehydrated bananas that did not char and maintained the quality needed for consumers ${ }^{[13]}$. Questions still remain on the durability and likely failure analysis of this technology and more analysis will be needed before any conclusions can be drawn. 


\section{Conclusion}

Based on previous research and current research, microwave assisted processing of wastes appears to show the greatest promise of the technologies. The present microwave drying system is sized to dewater wastes at rates of $150-175 \mathrm{~g} / \mathrm{hr}$. It has a number of advantages over conventional heating in that it is more energy efficient. Omar performed energy efficiency comparison for sludge dewatering and found that microwave drying was more efficient than convective drying by up to 20-36 times and 2.5 times more efficient than ohmic heating ${ }^{[15]}$. We do not have sufficient data to compare the energy efficiency but microwave heating gave much higher rates of water removal than the closed loop system.

Microwave heating presents problems with thermal runaway and charring when raw wastes are used but strong homogenization eliminates this problem. Thus, one may need to address pre-processing of wastes before microwave drying. Even though this adds an additional step, it may result in the potential for mixing all the wastes and processing all the wastes with a single microwave drying system.

A design for an automated microwave assisted waste processor with control systems for continuous feeding of homogenized wastes and with sensors to control the microwave functioning is presented. The possibility of new microwave technology such as the inverter technology would be worth evaluation together with some investigations into Ohmic heating.

\section{Acknowledgments}

Funding from NASA's ELS unit supported this work.

\section{References}

1. J.W. Fisher, J.A.Hogan, L. Delzeit, K. Wignarajah, R.Alba, G.Pace and T.G. Fox. (2009) Water Recovery from Wastes in Space Habitats - A Comparative Evaluation of SBIR Prototypes. Tech. Paper \# 2009-01-2342. $39^{\text {th }}$ International Conference on Environmental Systems, Savannah, GA July 2009

2. J. W. Fisher (2010) System Level Trades For Water Recovery. 2009 Annual Report. OPIS Project ID 52

3. G. Du, S. Wang and Z. Cai (2005) Microwave Drying of Wood Strands. Drying Technology 23: 1-16

4. S. K. Sastry, S. Jun, R. Somavat, C. Samaranayake, A. Yousef and R. B. Pandit (2009) Heating and Sterilization Technology for Long-Duration Space Missions: Transport Processes in a Reusable Package. Annals of the New York Academy of Sciences. 1161(1). 562-569.

5. S. Jun, B. Heskitt, S. Sastry, R. Mahna, J. Marcy and M. Perchonok (2005) Reheating and Sterilization Technology for Food, Waste and Water: Design and Development Considerations for Package and Enclosure. Tech. Paper \# 2005-012926. $35^{\text {th }}$ International Conference on Environmental Systems, Rome, Italy July 2005

6. K. Wignarajah, J. A. Hogan., J. W. Fisher, L. Delzeit and T. G. Fox. Evaluation of the Microwave Enhanced Freeze Drying Technology for Processing Solid Wastes. Tech. Paper \# 2008-01-2051. $38^{\text {th }}$ International Conference on Environmental Systems, San Francisco, CA June 2008

7. K. Wignarajah, R. Alba, J. W. Fisher, J. A. Hogan and T. G. Fox (2009) Investigations into Water Recovery from Solid Wastes using a Microwave Solid Waste Stabilization and Water Recovery System. Tech. Paper \# 2009-01-2341. 39 ${ }^{\text {th }}$ International Conference on Environmental Systems, Savannah, GA July 2009

8. J. M. R. Apollo-Arquiza Jean B. Hunter, Robert Morrow, and Ross Remiker, (2008) Modeling and Simulation of the Drying of Cabin Solid Waste in Long-Term Space Missions Tech. Paper \# 2008-01-2194. 38 ${ }^{\text {th }}$ International Conference on Environmental Systems, San Francisco, CA June 2008

9. R. R. Wheeler Jr., R. W. Dahl., N. M. Hadley,, D. B., Zavala Jr., T. W. Williams., J. R, Akse, and J. E. Atwater. Microwave Enhanced Freeze Drying of Solid Waste. Umpqua Research Company - Final Report Contract \# NNA05CP02C. December 2006. 
10. R. R. Wheeler Jr., N. M. Hadley, R.W Dahl., T. W. Williams, D. B. Zavala, Jr., and J. R. Akse. Microwave Enhanced Freeze Drying of Solid Waste. Tech Paper \# 2007-01-3266. $37^{\text {th }}$ International Conference on Environmental System., Chicago, IL July 2007

11. Jean B. Hunter, Robert Morrow, William Butrymowicz and J. M. R. Apollo-Arquiza. (2006) Energy Efficient Closed Loop Dryer for Solid Waste Stabilization on Long Duration Space Missions. Tech. Paper \# 2006-01-2088. $36^{\text {th }}$ International Conference on Environmental Systems, Norfolk, VA July 2006

12. R. Vadivambal and D. S. Jayas (2010) Non-uniform Temperature Distribution During Microwave Heating of Food Materials - A Review. Food Bioprocess Technology 3:161-171

13. N. R. Pereira, A. Marsaioli Jr and L. M. Ahrne (2007) Effect of Microwave Power, Air Velocity and Temperature on the Final Drying of Osmotically Dehydrated Bananas. J. Food Engineering 81(1); 79-87

14. E. Litwiller (2009) Solid and Liquid Waste Drying Bag. US Patent Pending

15. Wissam N. Omar (2004) Sludge Dewatering and Drying Using Microwave heating. M.Sc Thesis., Universiti Ptra Malaysia 